Article

\title{
Investigation of Two Novel Approaches for Detection of Sulfate Ion and Methane Dissolved in Sediment Pore Water Using Raman Spectroscopy
}

\section{Zengfeng Du ${ }^{1}$, Jing Chen ${ }^{1}$, Wangquan Ye ${ }^{1}$, Jinjia Guo ${ }^{1}$, Xin Zhang ${ }^{2}$ and Ronger Zheng ${ }^{1, *}$}

1 Optics and Optoelectronics Laboratory, Ocean University of China, Qingdao 266100, China; E-Mails: mofeng212@163.com (Z.D.); chenjingcj40@163.com (J.C.); jxyewaqu@163.com (W.Y.); opticsc@ouc.edu.cn (J.G.)

2 Key Lab of Marine Geology and Environment, Institute of Oceanology, Chinese Academy of Sciences, Qingdao 266071, China; E-Mail: xzhang@qdio.ac.cn

* Author to whom correspondence should be addressed; E-Mail: rzheng@ouc.edu.cn;

Tel./Fax: +86-532-6678-1211.

Academic Editor: Mark A. Arnold

Received: 7 March 2015 / Accepted: 12 May 2015 / Published: 26 May 2015

\begin{abstract}
The levels of dissolved sulfate and methane are crucial indicators in the geochemical analysis of pore water. Compositional analysis of pore water samples obtained from sea trials was conducted using Raman spectroscopy. It was found that the concentration of $\mathrm{SO}_{4}{ }^{2-}$ in pore water samples decreases as the depth increases, while the expected Raman signal of methane has not been observed. A possible reason for this is that the methane escaped after sampling and the remaining concentration of methane is too low to be detected. To find more effective ways to analyze the composition of pore water, two novel approaches are proposed. One is based on Liquid Core Optical Fiber (LCOF) for detection of $\mathrm{SO}_{4}{ }^{2-}$. The other one is an enrichment process for the detection of $\mathrm{CH}_{4}$. With the aid of LCOF, the Raman signal of $\mathrm{SO}_{4}{ }^{2-}$ is found to be enhanced over 10 times compared to that obtained by a conventional Raman setup. The enrichment process is also found to be effective in the investigation to the prepared sample of methane dissolved in water. $\mathrm{By} \mathrm{CCl}_{4}$ extraction, methane at a concentration below $1.14 \mathrm{mmol} / \mathrm{L}$ has been detected by conventional Raman spectroscopy. All the obtained results suggest that the approach proposed in this paper has great potential to be developed as a sensor for $\mathrm{SO}_{4}{ }^{2-}$ and $\mathrm{CH}_{4}$ detection in pore water.
\end{abstract}


Keywords: Raman spectroscopy; sulfate ion; methane; $\mathrm{LCOF}$; $\mathrm{CCl}_{4}$ extraction

\section{Introduction}

Seafloor sediments constitute some of the most extreme environments ever known $[1,2]$, and are characterized by low temperatures, high pressures and little oxygen. Due to the oxic conditions that prevail in the world's oceans, the dominant sulfur species in seawater is the sulfate ion $\left(\mathrm{SO}_{4}{ }^{2-}\right)$, which with a concentration of $29 \mathrm{mmol} / \mathrm{L}(2.71 \mathrm{~g} / \mathrm{kg})$ in seawater, the second most abundant anion [3], and it moves from the oceans to the sediments via various mechanisms. This makes marine sediments the main sink for seawater sulfate. Sulfate in marine sediments participates in the degradation of organic matter as a dominant electron acceptor until it is exhausted in the deeper subsurface sediment [4] where methanogenesis becomes the main terminal pathway of organic carbon mineralization [5]. Methane, as a stable end product of organic carbon mineralization, is produced exclusively by anaerobic archaea [6], and accumulates in subsurface sediments. Strong gradients in dissolved sulfate ion with depth are frequently observed, especially in the pore water that bathes gas hydrates. Methane slowly diffuses up to the sulfate zone, which is referred to as "sulfate-methane transition" (SMT), and reacts with sulfate in pore water. The coupled sulfate-methane reaction equation is $\mathrm{CH}_{4}+\mathrm{SO}_{4}{ }^{2-} \rightarrow \mathrm{HCO}_{3}{ }^{-}+\mathrm{H}_{2} \mathrm{~S}+\mathrm{H}_{2} \mathrm{O}$, and both the methane and sulfate are consumed to depletion. The sulfate concentration gradient in pore water can be taken as a universal indicator of depth to the sulfate-methane interface (SMI) [7], which is a fundamental biogeochemical redox boundary in methane-rich and methane-gas-hydrate-bearing marine sediments [8-11]. The anomaly of methane concentration is also regarded as evidence of the existence of natural gas hydrates [9].

Much of the geochemical knowledge sought does not come from the sediments themselves but from the pore waters that contain the signature of the reactions at work [12]. Geochemical studies in the deep ocean have traditionally relied upon sample recovery by bottles, cores, and dredges deployed from surface ships, or collected by manned submersibles and remotely operated vehicles (ROVs), to provide specimens for ship or shore based analysis [13]. Each year hundreds of ocean sediment cores are taken on purpose for geochemistry analysis [14]. However, it has been found that the methane concentrations differ greatly (up to $10^{3}$ ) in conventionally recovered cores and pore water sampling with pressurized core recovery [15]. Thus an in situ technique for geochemistry analysis is highly desirable.

Commercial methane sensors have been developed and used for methane monitoring and underwater detection. METS, as an electrochemical sensor, has been widely used for the detection of methane [16,17]. HydroC (Contros GmbH, Kiel, Germany) is also a commercial methane sensor, which is based on direct IR absorption spectroscopy [18]. Due to the stipulation that the targets must be gaseous methane, a gas-permeable membrane is indispensable for the two methane sensors, which limits the underwater application of the sensors.

Raman spectroscopy is regarded as a powerful technique for the geochemical analysis of pore water. This is especially true in the study of the oceanic gas hydrates near the seafloor. However, although the challenges of carrying out in situ Raman spectroscopy detection are formidable [13], in recent years, Raman spectroscopy applications for in situ detection have become increasingly popular. 
While in most instances, the concentration of methane in sea water is too low to be detected for conventional Raman spectroscopy, technologies for improving the sensitivity of Raman spectroscopy have been developed to broaden its underwater applications. In this paper, investigations for the improvement of the limit of detection for sulfate ion and methane dissolved in pore water using Raman spectroscopy have been carried out. Samples have been prepared in the laboratory (sodium sulfate solutions and saturated aqueous solution of methane) and pore water samples have been squeezed from sediment cores as samples for analysis. The potential application of Raman spectroscopy technology, based on the approaches proposed in this paper for in situ detection of sulfate ion and methane dissolved in pore water, is also discussed in this paper.

\section{Methods}

\subsection{The Principle of Raman Signal Enhancement}

The intensity of a solute's Raman signal in water can be described by Equation (1):

$$
R=K I \sigma P C
$$

where $R$ is the intensity of Raman signal, $K$ is a coefficient that is determined by the spectra acquisition system, $I$ is the excitation laser power, $\sigma$ is the Raman cross-section of the samples under investigation, $P$ is the effective optical path length, and $C$ is the molecular density of the sample [19]. $K, I$ and $\sigma$ are determined by the experimental setup, while $P$ can be improved in order to enhance the Raman signals of the samples. Due to the total internal reflection, the excitation laser is confined in the LCOF because of the total internal reflection, and the effective optical path length $(P)$ is significantly enhanced [20]. Thus, a better sensitivity can be achieved for Raman spectroscopy.

\subsection{Instrumental Setup}

A specific Raman spectroscopy setup with LCOF is established using commercially available components. The schematic diagram of experimental setup is presented in Figure 1. A diode-pumped, solid state laser that emits at $532 \mathrm{~nm}$ and outputs power at $300 \mathrm{~mW}$ is used as the light source (LMX-532S, from Oxxius, Lannion, France). The dichroic mirror in the dotted box is detachable in order to obtain Raman spectra of the samples using the conventional Raman spectroscopy experimental setup as well as the Raman experimental setup based on LCOF.

\subsection{Sampling}

The pore water samples were acquired in sea trials of "Science III", a research vessel that belongs to the Chinese Academy of Sciences Institute of Oceanology. A $2 \mathrm{~m}$ length sediment core was taken from

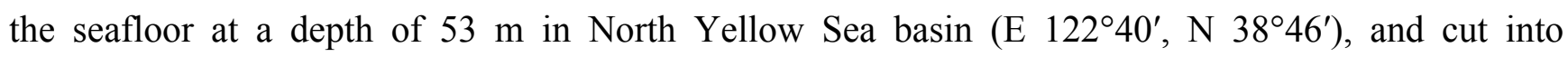
four pieces. The pore water samples were squeezed from different sediment pieces using an improved pore water sampler [21], and taken back to laboratory for Raman spectroscopy analysis.

In order to conduct quantitative analysis of $\mathrm{SO}_{4}{ }^{2-}$, a series of $\mathrm{Na}_{2} \mathrm{SO}_{4}$ solutions are prepared in $250 \mathrm{~mL}$ volumetric flasks, with $2,5,10,15,20,25,30,40,50$, and $60 \mathrm{mmol} / \mathrm{L}_{\text {of }} \mathrm{SO}_{4}{ }^{2-}$ respectively. The solutions are transferred into $5 \mathrm{~mL}$ cuvette for acquisition of Raman spectra in the conventional 
way when the dichroic mirror is placed in the optical path, and pumped into the LCOF for acquisition of Raman spectra when the dichroic mirror is removed from the optical path.

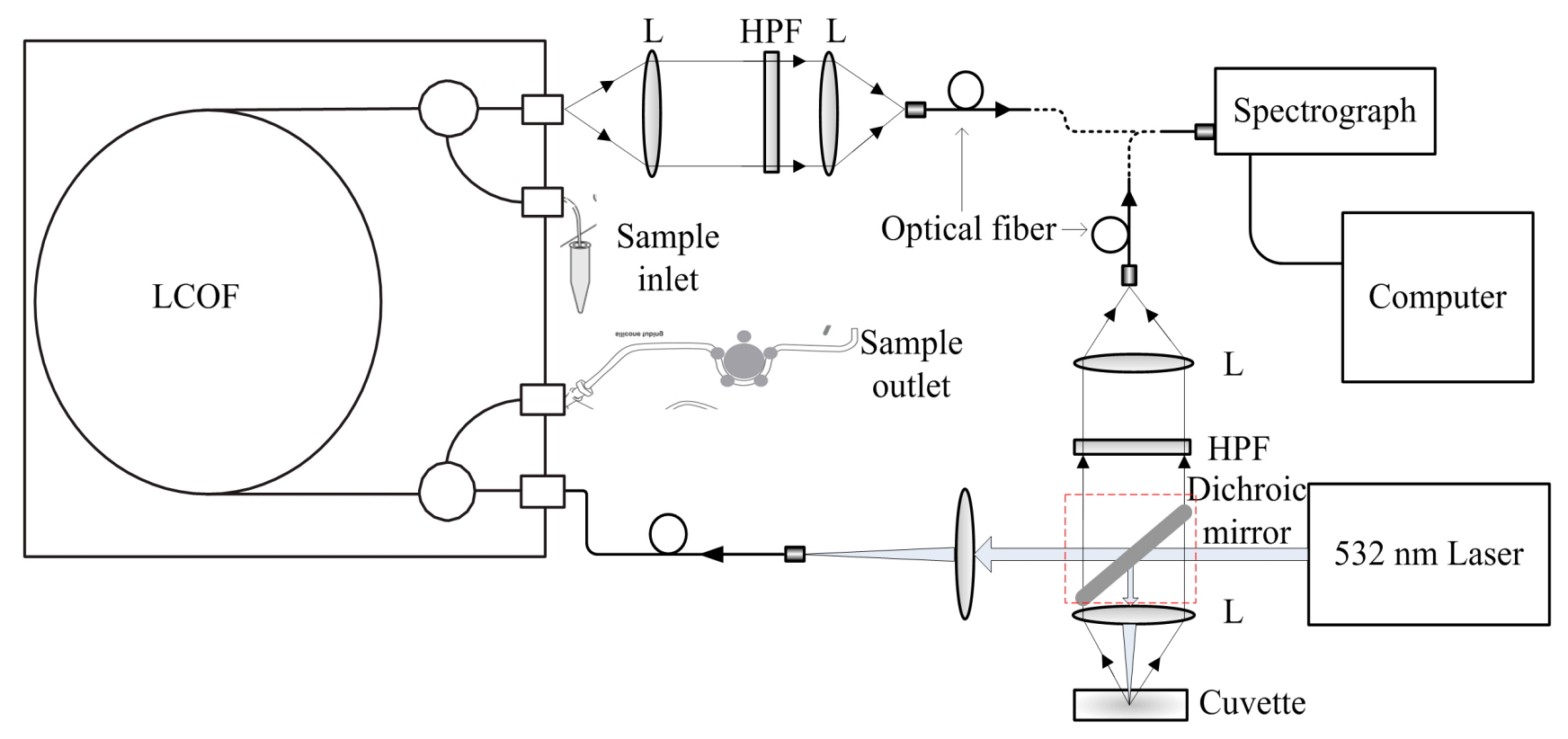

Figure 1. Schematic diagram of the LCOF-Raman experimental setup (R, dichroic mirror; L, optical lens; HPF, high pass filter).

To prepare a saturated aqueous solution of $\mathrm{CH}_{4}$ under laboratory conditions (the concentration of methane in water is about $1.14 \mathrm{mmol} / \mathrm{L}$ ), $\mathrm{CH}_{4}$ is pumped into deionized water (DI water) for $1 \mathrm{~h}$. During the enrichment process, $\mathrm{CCl}_{4}$ is injected into the saturated aqueous solution of $\mathrm{CH}_{4}$ and stirred for $0.5 \mathrm{~h}$. The solution is then left for $0.5 \mathrm{~h}$ so the water and $\mathrm{CCl}_{4}$ is separated in order to get the $\mathrm{CCl}_{4}$ solution after extraction. A magnetic stirring device (IKA-RCT basic model, IKA, Aachen, Germany) is employed to make the dissolution and extraction more efficient.

\subsection{Spectra Acquisition}

For each sample, 10 spectra are recorded and averaged for analysis. The background and the dark current are measured and automatically subtracted from each subsequent spectrum. The laser power is set at $0.3 \mathrm{~W}$. All the spectra are processed in Origin 8.1.

\section{Results and Discussion}

\subsection{Composition Analysis of Pore Water Samples with Different Depth}

A compact spectrometer (QE65000 Pro, from Ocean Optics, Dunedin, FL, USA) is used to acquire Raman spectra of pore water samples with an integration time of $1 \mathrm{~s}$, and the original Raman spectrum of the pore water samples is shown in Figure 2. The results show that the Raman peak of $\mathrm{SO}_{4}{ }^{2-}$ at 981 $\mathrm{cm}^{-1}$ is obviously detected, while the expected Raman peak of methane at $2917 \mathrm{~cm}^{-1}$ cannot be detected. A possible reason for this $\mathrm{s}$ that the methane dissolved in pore water has escaped after sampling and the concentration of the remaining methane is too low to be detected. 


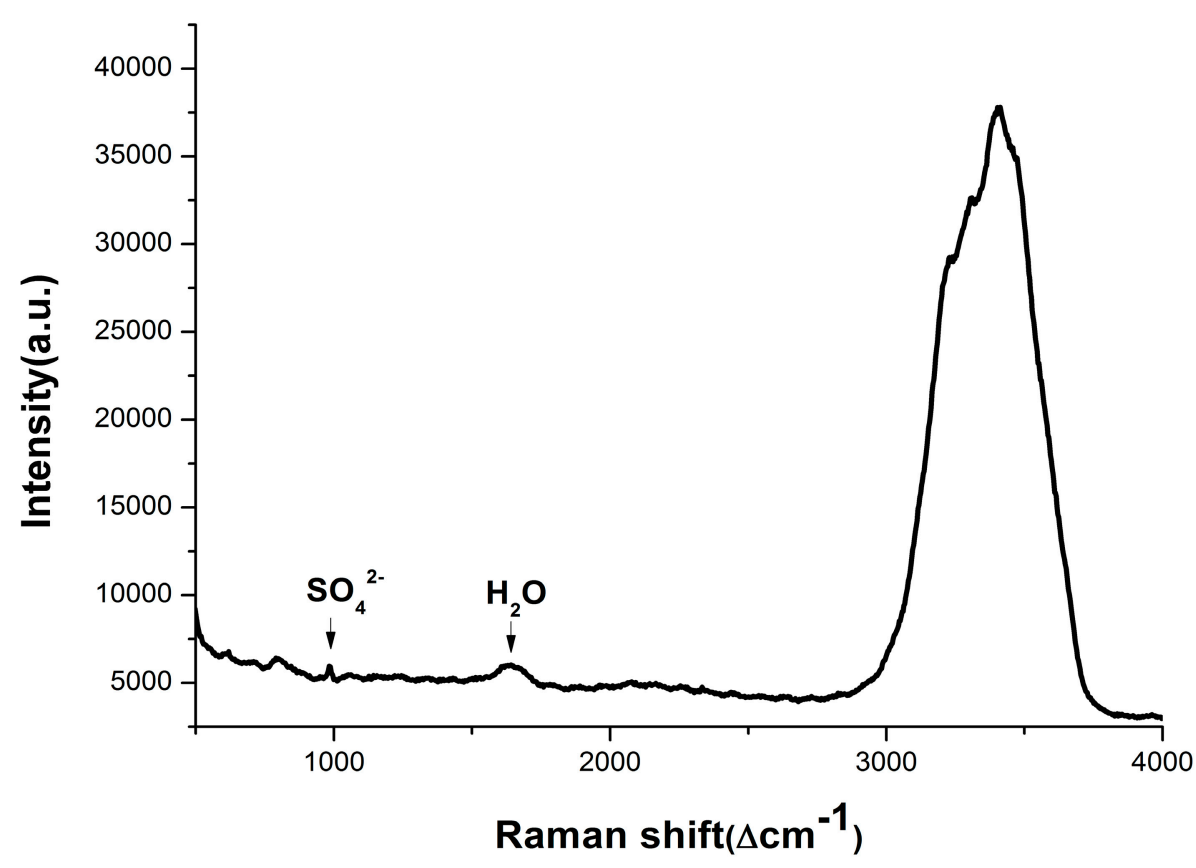

Figure 2. Typical Raman spectrum of the pore water samples.

The Raman spectra of the $\mathrm{Na}_{2} \mathrm{SO}_{4}$ solutions prepared in laboratory are acquired, and the internal standard normalization method is used in data processing. The Raman peak of $\mathrm{SO}_{4}{ }^{2-}$ (located at $981 \mathrm{~cm}^{-1}$ ) is normalized with the Raman peak of water molecular (located at $1640 \mathrm{~cm}^{-1}$ ) in this paper. The calibration curve is shown in Figure 3, and the fitted linear function is $R^{*}=0.012 C+0.534$, where $R^{*}$ is the normalized Raman intensity of $\mathrm{SO}_{4}{ }^{2-}, C$ is the concentration of the $\mathrm{SO}_{4}{ }^{2-}$.

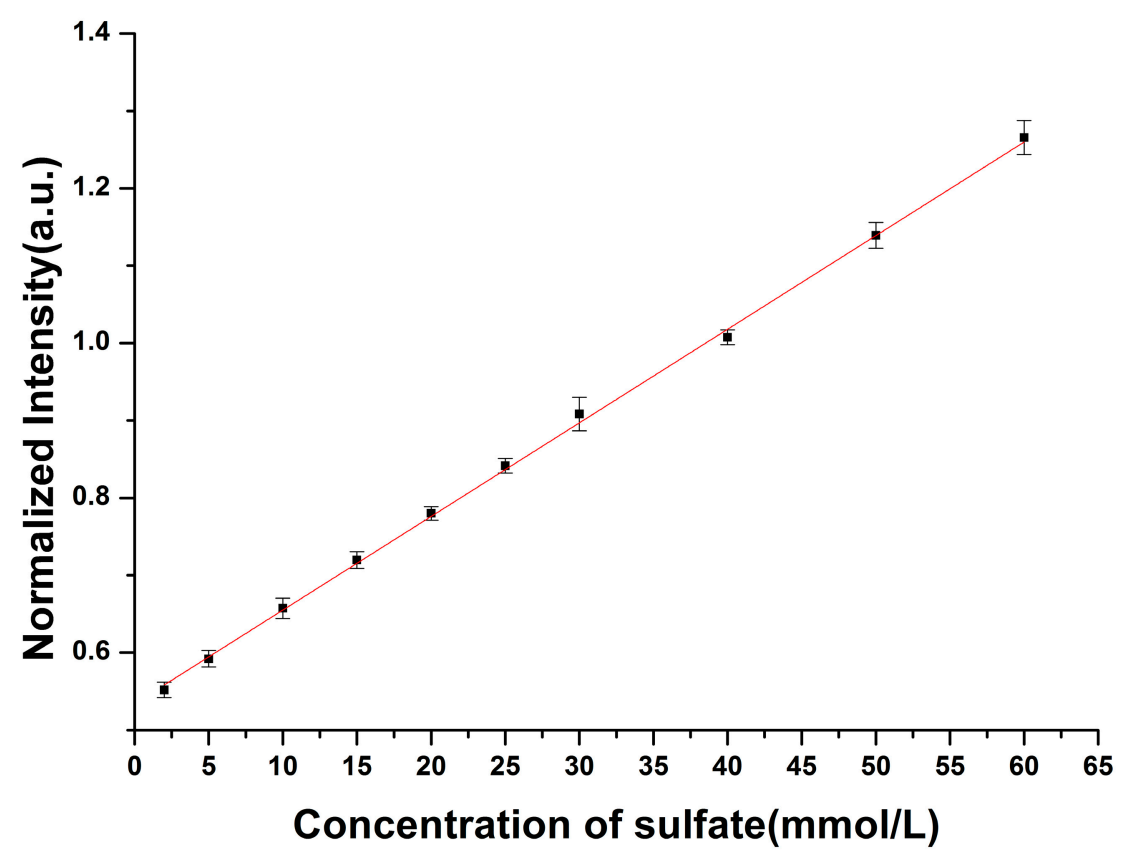

Figure 3. The calibration curve of sulfate concentration with conventional Raman spectroscopy.

Then the fitted linear function derived from the calibration curve, is used for quantitative analysis of the sulfate ion dissolved in pore water. According to the fitted linear function, concentrations of $\mathrm{SO}_{4}{ }^{2-}$ in pore water samples are obtained. The concentrations of $\mathrm{SO}_{4}{ }^{2-}$ in pore water are also measured by 
liquid chromatography. The results are demonstrated in Table 1, and the profiles of the $\mathrm{SO}_{4}{ }^{2-}$ concentrations in pore water is presented in Figure 4.

Table 1. Concentrations of $\mathrm{SO}_{4}{ }^{2-}$ in pore water samples measured by Raman spectroscopy and liquid chromatography.

\begin{tabular}{ccccc}
\hline \multirow{2}{*}{ Samples } & \multirow{2}{*}{ Sampling Depth $(\mathbf{c m})$} & \multicolumn{2}{c}{ Concentrations of $\mathbf{S O}_{4}{ }^{2-}(\mathbf{m m o l} / \mathbf{L})$} & \multirow{2}{*}{ Relative Deviation $\left|\mathbf{C}_{\text {Raman }}-\mathbf{C}_{\mathbf{L C}}\right| \mathbf{C}_{\mathbf{L C}}$} \\
\cline { 3 - 4 } & & $\mathbf{C}_{\text {Raman }}$ & $\mathbf{C}_{\mathbf{L C}}$ & $4.91 \%$ \\
A-12-a & $20-60$ & 27.1 & 28.5 & $11.54 \%$ \\
B-12-a & $60-100$ & 26.1 & 23.4 & $6.36 \%$ \\
C-12-a & $100-140$ & 25.1 & 23.6 & $1.76 \%$ \\
D-12-a & $140-180$ & 23.1 & 22.7 & \\
\hline
\end{tabular}

$\mathrm{C}_{\text {Raman }}$ concentrations measured by Raman spectroscopy; $\mathrm{C}_{\mathrm{LC}}$ concentrations measured by liquid chromatography.

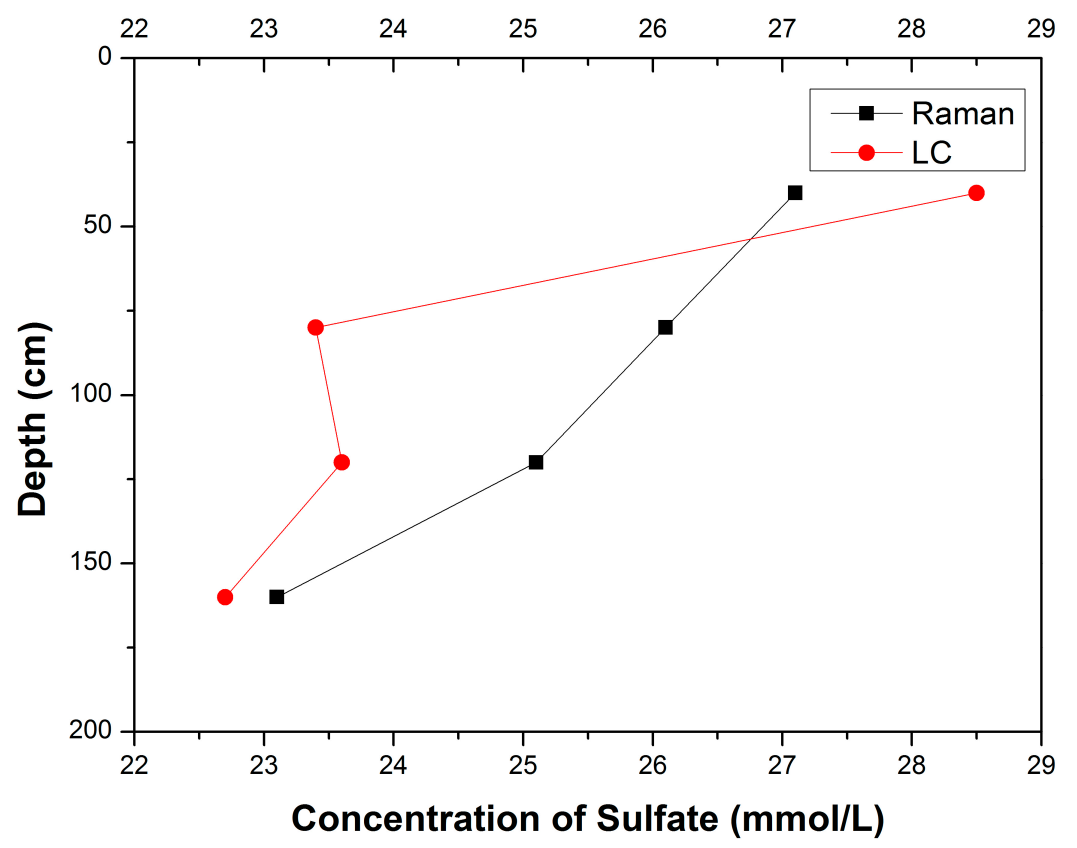

Figure 4. Profiles of $\mathrm{SO}_{4}{ }^{2-}$ concentrations in pore water measured by Raman spectroscopy and LC.

It can be seen that there is no significant difference between the concentrations of $\mathrm{SO}_{4}{ }^{2-}$ measured by Raman spectroscopy and LC, and the minimum relative deviation can reach $1.76 \%$. Figure 5 also shows that the concentration of $\mathrm{SO}_{4}{ }^{2-}$ in pore water decreases as the depth increases, which indicates the existence of sulfate reduction in sediments. Because of the sulfate-methane reaction, the sulfate could be exhausted in the deeper sediment [5]. Furthermore, the concentration of $\mathrm{SO}_{4}{ }^{2-}$ would be too low to be detected for Raman spectroscopy. Thus, an enhancement technology for Raman signal of $\mathrm{SO}_{4}{ }^{2-}$ is highly desired for geochemical analysis of pore water.

\subsection{Enhancement for Raman Signal of $\mathrm{SO}_{4}{ }^{2-}$ with $\mathrm{LCOF}$}

It is reported that up to a 100-fold improvement of Raman signals can be observed using the LCOF-Raman experimental setup compared to the conventional Raman experimental setup [22], and the performance of different LCOF geometries differs greatly [23]. 


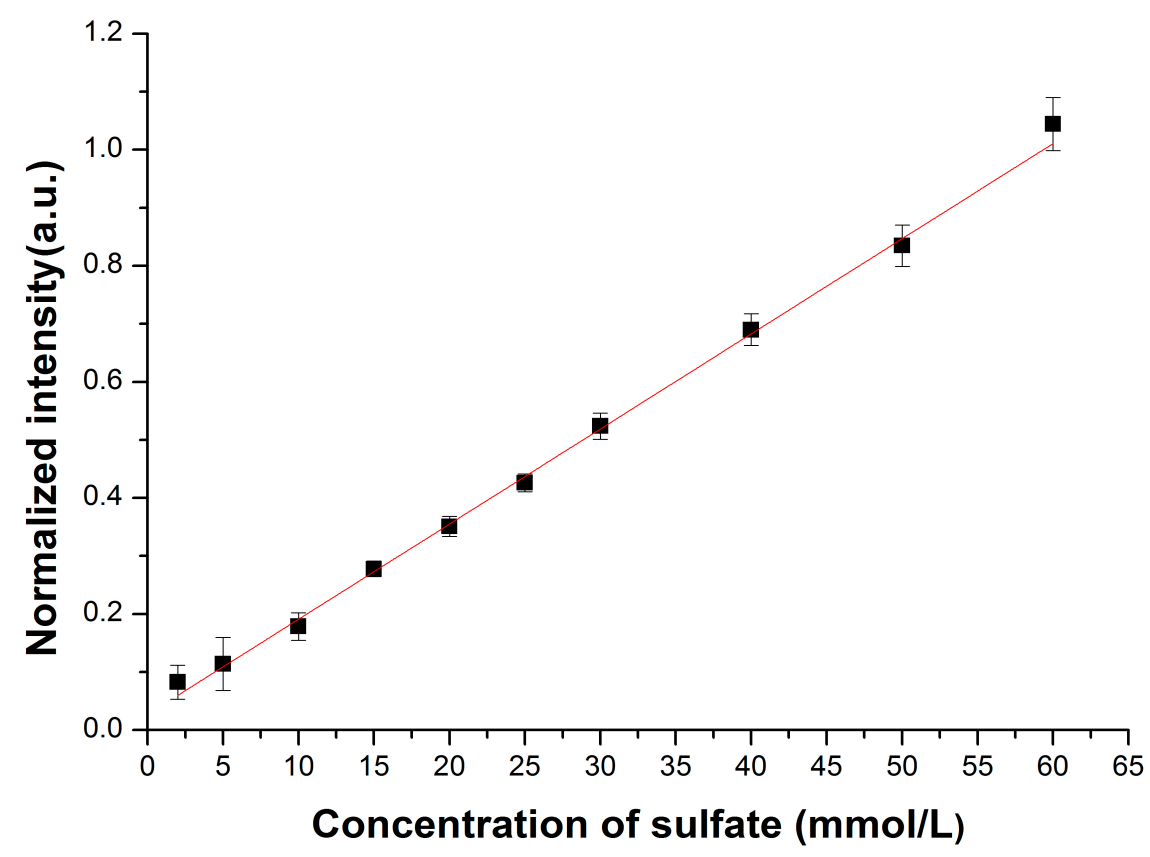

Figure 5. The calibration curve of sulfate concentration with LCOF-Raman spectroscopy.

A special LCOF-Raman experimental setup is established in laboratory. The physical length of the LCOF is about $100 \mathrm{~cm}$ (LWCC-2100, from Ocean Optics), and the spectrometer is a QE65000 Pro (from Ocean Optics) with an integration time of $1 \mathrm{~s}$ for each measurement. Raman spectra of the $\mathrm{Na}_{2} \mathrm{SO}_{4}$ solutions prepared in laboratory are also acquired by the LCOF-Raman experimental setup. The internal standard normalization method is used in data processing. The calibration curve is shown in Figure 5, and the fitted linear function is $R^{*}=0.016 C+0.027$. Table 2 presents the limit of detection (LOD) of the conventional Raman and the LCOF-Raman experimental setups.

Table 2. The fitted linear functions and LODs of conventional Raman and LCOF-Raman experimental setup. (QE65000 is employed as spectrometer, and the length of the LCOF is $100 \mathrm{~cm}$.)

\begin{tabular}{ccc}
\hline & Fitted Linear Function & LOD (mmol/L) \\
\hline Conventional Raman setup & $R^{*}=0.012 C+0.534$ & 2.15 \\
LCOF-Raman setup & $R^{*}=0.016 C+0.027$ & 1.50 \\
\hline
\end{tabular}

Figure 6 shows the Raman spectra of $30 \mathrm{mmol} / \mathrm{L}$ solution of $\mathrm{Na}_{2} \mathrm{SO}_{4}$ using both the LWCC-2100 and a cuvette as sample container. The solid line is the Raman spectrum acquired by the LCOF-Raman (LWCC-2100) setup, while the dashed-dot line is the Raman spectrum acquired by the conventional Raman setup as a comparison. The backgrounds are subtracted for both spectra. The comparison of the spectra shows an increase in the Raman signal using the LCOF: the peak intensity and area are amplified by approximately two fold. 


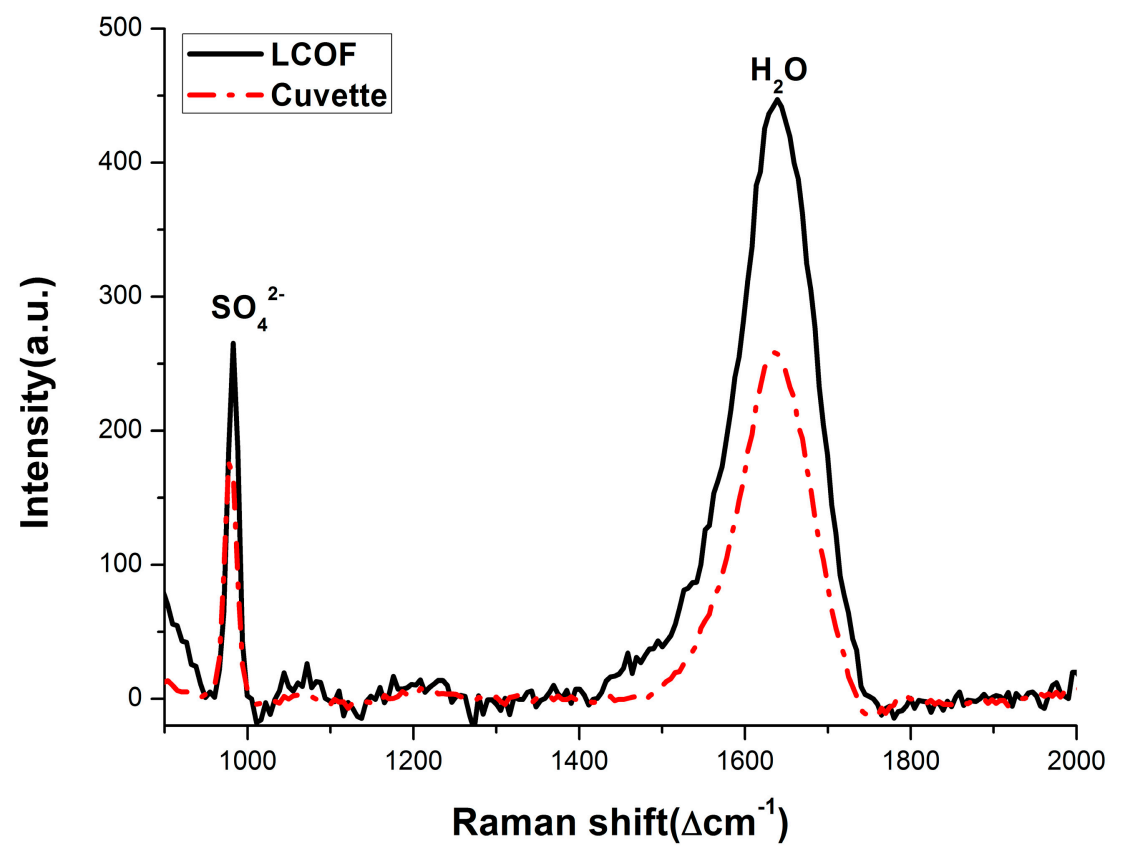

Figure 6. Raman spectra of $30 \mathrm{mmol} / \mathrm{L}$ sulfate solution using the LCOF-Raman experimental (LWCC-2100) setup and conventional experimental setup, respectively. The Raman peak of $\mathrm{SO}_{4}{ }^{2-}$ is located at $981 \mathrm{~cm}^{-1}$, and the Raman peak of $\mathrm{H}_{2} \mathrm{O}$ is located at $1640 \mathrm{~cm}^{-1}$.

In another updated setup, a LCOF (LWCC-3050, from Ocean Optics) with the same samples $\left(\mathrm{Na}_{2} \mathrm{SO}_{4}\right.$ water solutions prepared in laboratory) pumped in and with $50 \mathrm{~cm}$ physical length, has been chosen for comparison. To achieve a better performance, a more sensitive spectrometer (PPO Raman, from P\&P Optica, Waterloo, ON, Canada) together with a $2000 \times 256$ back illuminated CCD (DU416A-LDC-DD, from Andor Technology, Belfast, UK) is used. The spectra are averaged from ten measurements taken with an integration time of $0.1 \mathrm{~s}$ for each measurement. Then the calibration curves of sulfate concentration with the conventional Raman and LCOF-Raman spectroscopy can be obtained.
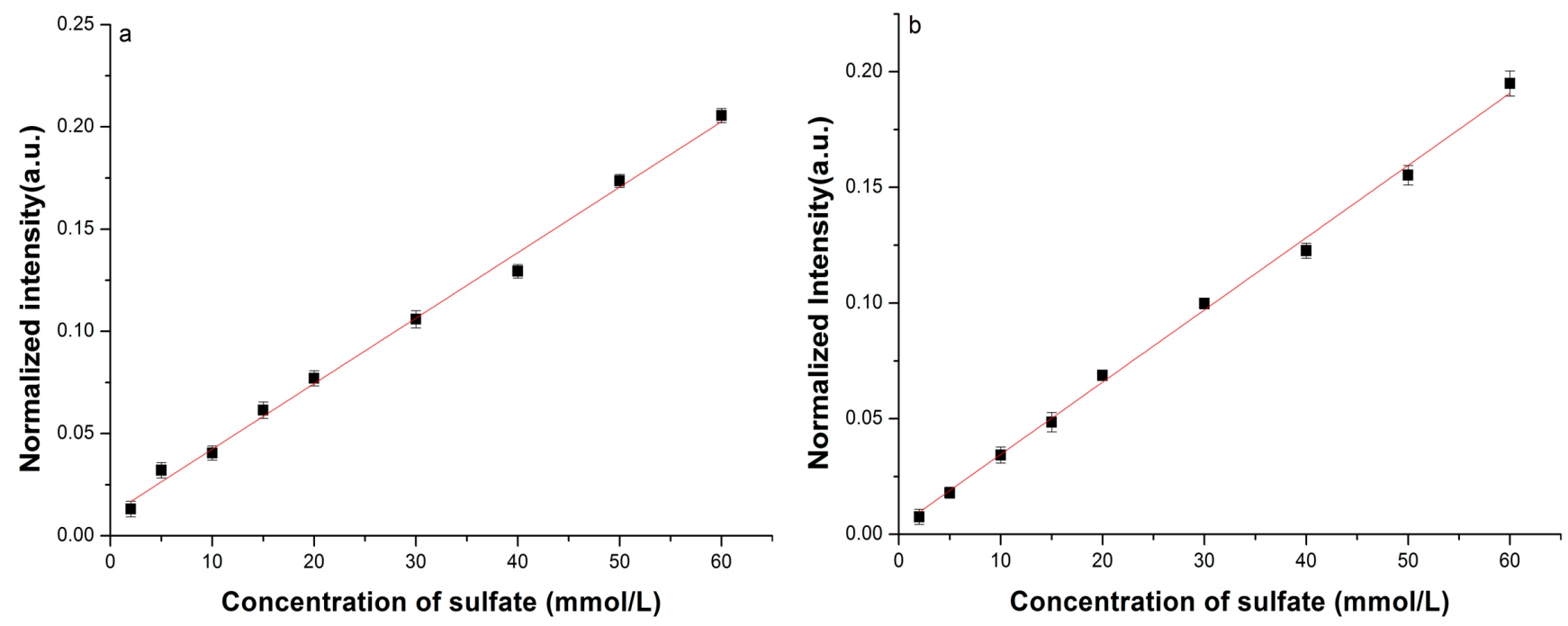

Figure 7. The calibration curve of sulfate concentration with (a) conventional Raman spectroscopy and (b) LCOF-Raman spectroscopy. 
Table 3. The fitted linear functions and LODs of conventional Raman and LCOF-Raman experimental setup. (PPO Raman is employed as spectrometer, and the length of the LCOF is $50 \mathrm{~cm}$.)

\begin{tabular}{ccc}
\hline & Fitted Linear Function & LOD (mmol/L) \\
\hline Conventional Raman setup & $R^{*}=0.0032 C+0.010$ & 1.80 \\
LCOF-Raman setup & $R^{*}=0.0031 C+0.0034$ & 0.35 \\
\hline
\end{tabular}

Figure 7 shows the calibration curves, and Table 3 presents the LOD of the conventional Raman and the LCOF-Raman experimental setups. Figure 8 shows the typical Raman spectra obtained using both LWCC-3050 and cuvette as sample containers, with solid line and dash-dot line represented respectively. It can be seen from Figure 8 that the Raman signal of $\mathrm{SO}_{4}{ }^{2-}$ obtained with the LCOF-Raman setup is much higher than that with conventional Raman setup. Over 10-fold enhancement is achieved with the LCOF approach.

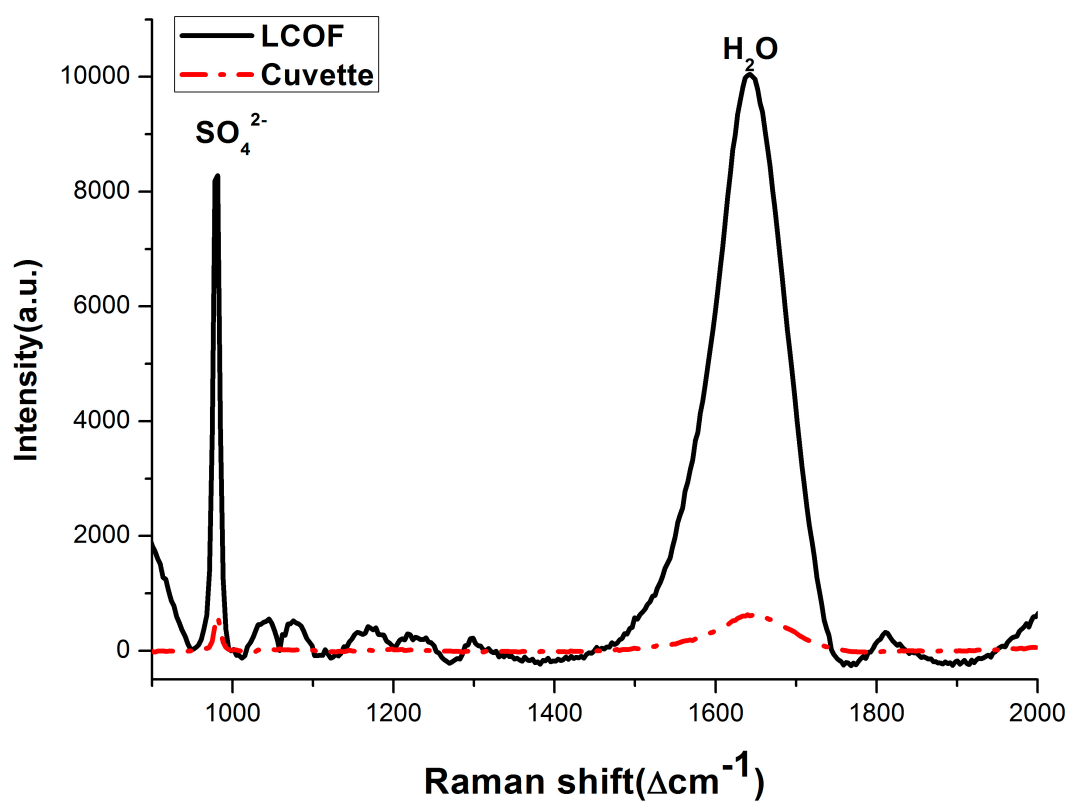

Figure 8. Raman spectra of $30 \mathrm{mmol} / \mathrm{L}$ sulfate solution using the LCOF-Raman experimental (LWCC-3050) setup and conventional experimental setup respectively.

Tables 2 and 3 present the LODs of the Raman experimental setups, and it is found that the LOD of Raman spectroscopy can be improved with LCOF assistance. The obtained results indicate that the physical length of the LCOF has a great influence on the enhancement of the Raman signals. It seems that the $50 \mathrm{~cm}$ LCOF has a better Raman signal enhancement than the $100 \mathrm{~cm}$ LCOF.

\subsection{Dissolved Methane Detection Aided with an Enrichment Process}

As is known, the maximum concentration of dissolved methane is about $1.14 \mathrm{mmol} / \mathrm{L}$ (the concentration of its saturated solution under laboratory conditions), which is still too low to be detected by the LCOF-Raman (LWCC-3050) experimental setup. In order to detect the methane dissolved in water, an approach based on $\mathrm{CCl}_{4}$ extraction is introduced in this work. $\mathrm{CCl}_{4}$ is chosen as an extraction agent for two reasons: the solubility of $\mathrm{CH}_{4}$ in $\mathrm{CCl}_{4}$ is much larger than that in $\mathrm{H}_{2} \mathrm{O}$ and 
$\mathrm{CCl}_{4}$ is immiscible with water. Thus, the trace $\mathrm{CH}_{4}$ dissolved in water is enriched into $\mathrm{CCl}_{4}$ after the extraction. Then, the $\mathrm{CCl}_{4}$ after extraction is taken as samples for Raman spectrum acquisition. The molecular density of $\mathrm{CH}_{4}\left(\mathrm{C}\right.$ in Equation (1)) in $\mathrm{CCl}_{4}$ is much bigger than that in $\mathrm{H}_{2} \mathrm{O}$. Finally, the Raman spectrum of $\mathrm{CCl}_{4}$ after the extraction acquired by the conventional experimental setup with an integration time of $0.1 \mathrm{~s}$, which is an average result of ten measurements, is shown in Figure 9.

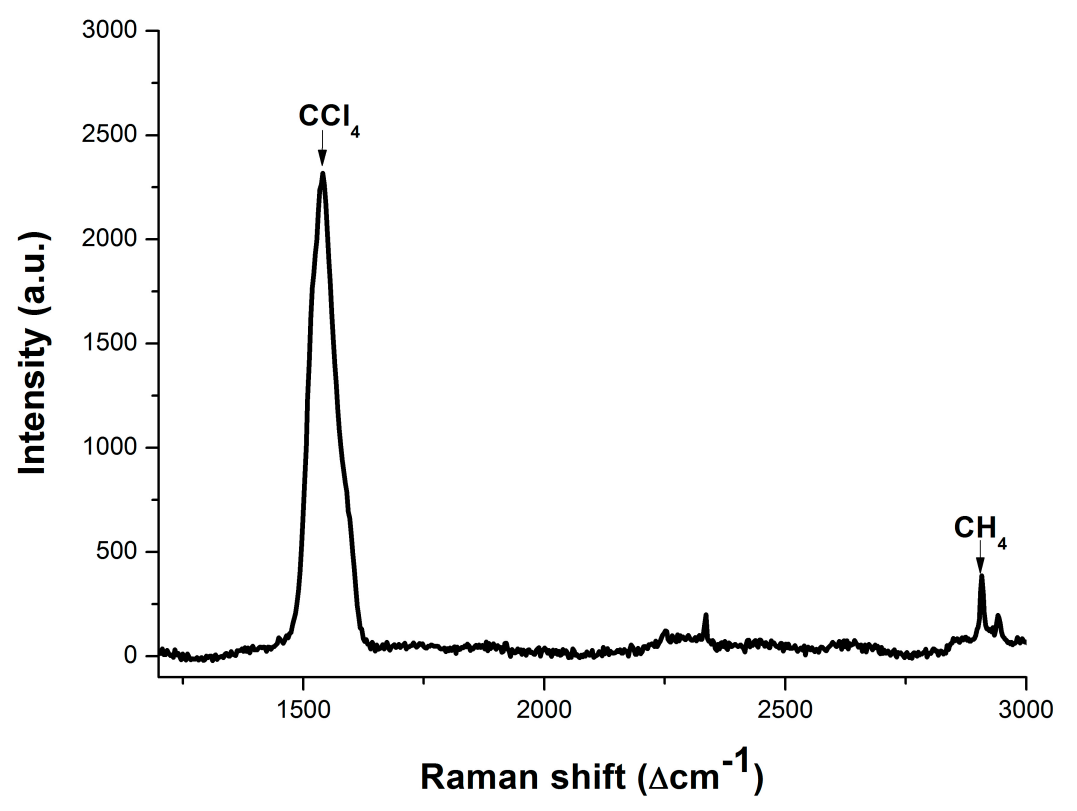

Figure 9. Raman spectrum of $\mathrm{CCl}_{4}$ after extraction after conventional experimental setup.

The Raman peak of methane is located at $2907 \mathrm{~cm}^{-1}$ and can be clearly observed in Figure 9 . This indicates that, after the extraction, the methane dissolved in water is enriched into the $\mathrm{CCl}_{4}$. The preliminary result shows that the methane dissolved in water with concentration below $1.14 \mathrm{mmol} / \mathrm{L}$ could be indirectly detected assisted by $\mathrm{CCl}_{4}$ extraction. There are still many opportunities for optimizing this approach, and there is a long way to go in order to achieve a quantitative analysis of methane dissolved in water.

\section{Conclusions}

For the compositional analysis of pore water, Raman spectra of the pore water samples obtained from the sea trials were acquired. According to the linear function obtained from the calibration curve, the concentration of $\mathrm{SO}_{4}{ }^{2-}$ in pore water is inversely calculated according to the linear function obtained from the calibration curve. It is found that the concentration of $\mathrm{SO}_{4}{ }^{2-}$ in pore water samples decreases as the depth increases. However, methane cannot be detected using Raman spectroscopy because of its low concentration. Two approaches are proposed and used for a better analysis of pore water samples. One approach uses a LCOF as a sample container to enlarge the optical path length for detection of $\mathrm{SO}_{4}{ }^{2-}$. The other approach is an enrichment process for methane with $\mathrm{CCl}_{4}$ extraction. With the assistance of a LCOF whose physical length is $50 \mathrm{~cm}$, the LOD of Raman spectroscopy is significantly improved, and the Raman signal of $\mathrm{SO}_{4}{ }^{2-}$ is amplified over 10 times compared to that obtained with a conventional Raman experimental setup. By the means of extraction, the trace methane dissolved in water is enriched into $\mathrm{CCl}_{4}$ because the solubility of methane in water and $\mathrm{CCl}_{4}$ differs immensely. Hence the 
methane dissolved in water with concentration below $1.14 \mathrm{mmol} / \mathrm{L}$ could be indirectly detected. There are still opportunities to optimize the performance of these two approaches. Furthermore, all of the obtained results suggest that the proposed approaches in this paper have great potential to be developed to a sensor for detection of sulfate ion and methane dissolved in sediment pore water.

\section{Acknowledgments}

The work was supported by National High Technology Research and Development Program of China (Grant No. 2012AA09A405) and Natural Science Foundation of China (Grant No. 41006059).

\section{Author Contributions}

Ronger Zheng supervised the research project and revised the draft. Zengfeng Du and Jinjia Guo proposed the idea. Xing Zhang provided the pore water samples and discussed the results. Zengfeng $\mathrm{Du}$ and Wangquan Ye performed the experiments. Jing Chen processed the data. Zengfeng Du wrote the manuscript.

\section{Conflicts of Interest}

The authors declare no conflict of interest.

\section{References}

1. Prieur, D.; Erauso, G.; Jeanthon, C. Hyperthermophilic life at deep-sea hydrothermal vents. Planet. Space Sci. 1995, 43, 115-122.

2. Simoneit, B.R.T.; Schoell, M.; Dias R.F.; de Auuino Neto, F.R. Unusual carbon isotope compositions of biomarker hydrocarbons in a Permian tasmanite. Geochim. Cosmochim. Acta 1993, 57, 4205-4211.

3. Vairavamurthy, M.A.; Orr, W.L.; Manowitz, B. Geochemical transformations of sedimentary sulfur: An introduction. In ACS Symposium Series; American Chemical Society: Washington, DC, USA, 1995; pp. 1-15.

4. Henrichs, S.M.; Reeburgh, W.S. Anaerobic mineralization of marine sediment organic matter: Rates and the role of anaerobic processes in the oceanic carbon economy. Geomicrobiol. J. 1987, $5,191-237$.

5. Jorgensen, B.B.; Kasten, S. Sulfur Cycling and Methane Oxidation. In Marine Geochemistry; Horst, D.S., Matthias, Z., Eds.; Springer: Berlin/Heidelberg, Germany, 2006; pp. 271-309.

6. Whitman, W.B.; Bowen, T.L.; Boone, D.R. The methanogenic bacteria. In The Prokaryotes; Dworkin, M., Balows, A., Eds.; Springer US: New York, NY, USA, 2006; pp. 165-207.

7. Borowski, W.S.; Paull, C.K.; Ussler, W. Carbon cycling within the upper methanogenic zone of continental rise sediments; an example from the methane-rich sediments overlying the Blake Ridge gas hydrate deposits. Mar. Chem. 1997, 57, 299-311.

8. Claypool, G.E.; Kaplan, I.R. The origin and distribution of methane in marine sediments. In Natural Gases in Marine Sediments; Isaac, R.K., Ed.; Springer US: New York, NY, USA, 1974; pp. 99-139. 
9. Borowski, W.S.; Paull, C.K.; Ussler, W. Marine pore-water sulfate profiles indicate in situ methane flux from underlying gas hydrate. Geology 1996, 24, 655-658.

10. Borowski, W.S.; Paull, C.K.; Ussler, W. Global and local variations of interstitial sulfate gradients in deep-water, continental margin sediments: Sensitivity to underlying methane and gas hydrates. Mar. Geol. 1999, 159, 131-154.

11. Ussler, W.; Paull, C.K. Rates of anaerobic oxidation of methane and authigenic carbonate mineralization in methane-rich deep-sea sediments inferred from models and geochemical profiles. Earth Planet. Sci. Lett. 2008, 266, 271-287.

12. Zhang, X.; Walz, P.M.; Kirkwood, W.J.; Hester, K.C.; Ussler, W.; Peltzer, E.T.; Brewer, P.G. Development and deployment of a deep-sea Raman probe for measurement of pore water geochemistry. Deep Sea Res. Part I Oceanogr. Res. Pap. 2010, 57, 297-306.

13. Brewer, P.G.; Malby, G.; Pasteris, J.D.; White, S.N.; Peltzer, E.T.; Wopenka, B.; Freeman, J.; Brown, M.O. Development of a laser Raman spectrometer for deep-ocean science. Deep Sea Res. Part I Oceanogr. Res. Pap. 2004, 51, 739-753.

14. Reeburgh, W.S. Oceanic Methane Biogeochemistry. Chem. Rev. 2007, 107, 486-513.

15. Paull, C.K.; Ussler, W. History and Significance of Gas Sampling During DSDP and ODP Drilling Associated with Gas Hydrates. In Natural Gas Hydrates: Occurrence, Distribution, and Detection; Paull, C.K., Dillon, W.P., Eds.; American Geophysical Union: Washington, DC, USA, 2001; pp. 53-65.

16. Newman, K.R.; Cormier, M.H.; Weissel, J.K.; Driscoll, N.W.; Kastner, M.; Solomon, E.A.; Robertson, G.; Hill, J.C.; Singh, H.; Camilli, R.; et al. Active methane venting observed at giant pockmarks along the US mid-atlantic shelf break. Earth Planet. Sci. Lett. 2008, 267, 341-352.

17. Marinaro, G.; Etiope, G.; Bue, N.L.; Favali, P.; Papatheodorou, G.; Christodoulou, D.; Furlan, F.; Gasparoni, F.; Ferentinos, G.; Masson, M.; et al. Monitoring of a methane-seeping pockmark by cabled benthic observatory (Patras Gulf, Greece). Geo-Mar. Lett. 2006, 26, 297-302.

18. Fietzek, P.; Kramer, S.; Esser, D. Deployments of the HydroC ${ }^{\mathrm{TM}}\left(\mathrm{CO}_{2} / \mathrm{CH}_{4}\right)$ on stationary and mobile platforms-Merging trends in the field of platform and sensor development. In Proceedings of the IEEE OCEANS, Waikoloa, HI, USA, 19-22 September 2011; pp. 1-9.

19. Pelletier, M.J. Analytical Applications of Raman Spectroscopy; Blackwell Science Ltd.: Osney Mead, Oxford, UK, 1999; p. 478.

20. Altkorn, R.; Koev, I.; van Duyne, R.P.; Litorja, M. Low-loss liquid-core optical fiber for low-refractive-index liquids fabrication, characterization, and application in Raman spectroscopy. Appl. Opt. 1997, 36, 8892-8898.

21. Reeburgh, W.S. An improved interstitial water sampler. Limnol. Oceanogr. 1967, 12, 163-165.

22. Qi, D.; Berger, A.J. Quantitative analysis of Raman signal enhancement from aqueous samples in liquid core optical fibers. Appl. Spectrosc. 2004, 58, 1165-1171.

23. Altkron, R.; Malinsky, M.D.; van Duyne, R.P.; Koev, I. Intensity considerations in liquid core optical fiber Raman spectroscopy. Appl. Spectrosc. 2001, 55, 373-381.

(C) 2015 by the authors; licensee MDPI, Basel, Switzerland. This article is an open access article distributed under the terms and conditions of the Creative Commons Attribution license (http://creativecommons.org/licenses/by/4.0/). 